\title{
Increasing the innovative potential of the enterprise building complex
}

\author{
Iuliia Artamonova ${ }^{1,{ }^{*}}$ and Boris Khrustalev ${ }^{1}$ \\ ${ }^{1}$ Penza State University of Architecture and Construction, 440028, Titova Street, 28, Penza, Russia
}

\begin{abstract}
The article discusses the structure and methodology for assessing the innovative potential of an enterprise. Based on expert analysis, factors affecting its innovative potential are highlighted. The article can be useful to researchers and managers of construction companies in assessing their innovative potential.
\end{abstract}

\section{Introduction}

The construction industry of Russia, as well as other developed countries, is distinguished by a high degree of conservatism and a low level of innovation.

The low susceptibility of construction companies to innovations, in turn, is caused by a high level of risk associated with the potential shortcomings of new products, which may cause harm to the environment and people's lives, as well as property of individuals or legal entities, state or municipal property. The duration of the life cycle of capital construction projects takes dozens of years, thus hindering the assessment of the effectiveness of new materials, technologies and construction methods, which significantly distinguishes the construction industry from others. Another reason for the passivity of the construction industry is the lack of increased interest, since most developers believe that high income can be obtained without using innovation in a favorable market environment.

Russia, having a huge educational and scientific potential, according to official estimates, occupies only $0.3 \%$ of the world market for civilian high-tech products, while the share of the United States is 36\%, and Japan - 30\%.

Russia has great potential for innovation in the creation of new technologies. But for this, it is necessary to effectively develop the innovation potential and increase the direction of the scientific and technical progress of the construction complex.

It is innovative development that has the impetus to improve its position in the market in conditions of limited natural resources, in a changing economic environment and the existing high competition from many companies. In recent years, Russia has embarked on a comprehensive implementation of the program for the innovative development of its economy. According to the program, a national innovation system will be created in Russia, which will be the basis for ensuring technological and economic security and modernization of the country's economy. When creating such a program, it is necessary to take into account that the perception of the country's economy as a whole and its individual

\footnotetext{
* Corresponding author: clusterwings@mail.ru
} 
construction organizations do not correspond to the outcome of innovation, that is, they do not coincide with the set strategic goals and specific objectives of the country [1-3].

Innovative development of the enterprise depends on how the technological system of the enterprise is ready to accept this or that innovative task, to correctly evaluate it. The perception of an innovation task may take the form of recognizing innovations when the production system is interested and prepared for their implementation, or denying innovations when they contradict the interests of the enterprise, or when the production system is not ready for their implementation and the control subsystem lacks effective leverage.

\section{Problem statement and research}

In modern conditions, the development of business entities becomes more dependent on the effective use of innovations. It is the successful introduction of innovations that contributes to economic growth. The issue of increasing the innovation potential is one of the most important in modern economic relations.

As mentioned earlier, the innovation potential is a subsystem of the integral potential, which includes:

-the level of scientific and technological development, where the main factors for the development of scientific and technological progress are the intellectual potential of society. It is expressed in the number of scientists, in the degree of education and the general culture of the nation, as well as the level of development of the scientific and industrial base. Among them, the most important factor, the engine of scientific and technological progress is science.

The innovation potential of the enterprise is influenced by factors of external and internal environment.

These factors include:

-organizational and institutional mechanisms are the financing of $\mathrm{R} \& \mathrm{D}$, the number of inventions and patents granted, the budget, etc.

-investments include the costs of implementing measures of innovative development, the volume of foreign direct and budgetary investments.

- personnel resources - directly the cost of raising the level of education, increasing the share of workers with qualifications.

-factors and conditions of the external and internal environment consider the indicators of the utility of innovation, labor productivity at the enterprise in the building complex.

The external factors include factors that ensure the interaction of the enterprise with the economic and social environments:

-use of external sources to support all phases of the innovation process: from discovery and development to commercialization;

-communications with customers, business partners, investors, competitors, research organizations and universities;

Lobbying of interests in state institutional structures.

Internal factors are the essential features of an enterprise that distinguish it from competitors and determine its innovative viability: motivated leadership;

-integration of technological, organizational and managerial innovations;

-high performance;

-effective relations with the staff, its wide involvement in the innovation process;

- continuous organizational learning;

-effective marketing system that communicates with end users;

- quality management, infrastructure, organizational development. 
Table 1. Environmental factors influencing the innovative development of construction enterprises.

\begin{tabular}{|c|c|}
\hline $\begin{array}{l}\text { Group of } \\
\text { factors }\end{array}$ & Factors \\
\hline $\begin{array}{l}\text { Organizati } \\
\text { onal and } \\
\text { economic }\end{array}$ & $\begin{array}{l}\text {-economic state of the region } \\
\text {-economic condition of the building complex } \\
\text {-the presence of venture investors and financial resources in the region } \\
\text { - level of prices for construction objects } \\
\text {-economic policy of credit institutions in the region } \\
\text {-efficiently formed tax space of the region } \\
\text {-the presence of economic ties with other regions } \\
\text {-the presence of a developed regulatory framework in the field of construction } \\
\text { - the level of demand for products manufactured by enterprises and potential } \\
\text { demand for objects of innovation } \\
\text {-geographic location of the region, in particular the territory, climate, terrain, } \\
\text { soil, etc. }\end{array}$ \\
\hline $\begin{array}{l}\text { Administr } \\
\text { ative and } \\
\text { manageria } \\
1\end{array}$ & $\begin{array}{l}\text {-the presence in the region of the mechanism for the commercialization of } \\
\text { innovations (technology parks, business incubators, technology transfer } \\
\text { centers), including in construction } \\
\text {-the presence in the region of infrastructure management innovation in } \\
\text { construction } \\
\text {-the presence in the region of progressive legislation regulating innovation, } \\
\text { including in construction. }\end{array}$ \\
\hline Scientific & $\begin{array}{l}\text {-the presence in the region of conditions for the development of science in the } \\
\text { field of construction (universities, design institutes, research institutes) } \\
\text {-the presence in the region of the mechanism of technology transfer to the } \\
\text { construction and its level } \\
\text {-the level of development of the system of training in the field of construction } \\
\text { and the degree of its interaction with university science. }\end{array}$ \\
\hline $\begin{array}{l}\text { Technical } \\
\text { and } \\
\text { technologi } \\
\text { cal }\end{array}$ & $\begin{array}{l}\text { - architectural features of the region } \\
\text { - production potential of construction companies in the region } \\
\text { - readiness of enterprises of the building complex to introduce innovations } \\
\text { - the level of development of communication links between the branches of the } \\
\text { building complex } \\
\text {-development of industrial base in the region } \\
\text { - mineral and raw material base of the region } \\
\text {-the level of transport infrastructure development } \\
\text {-the level of transport infrastructure development }\end{array}$ \\
\hline
\end{tabular}

In 2017, the construction complex of the Penza Region is represented by 2,300 organizations (in 2016, 2,075 organizations).

The reason for the growth in the number of enterprises was, among other things, the tendency towards the reorganization of large construction companies and the separation of industries into separate businesses.

The environmental factors affecting the innovative development of construction enterprises are determined.

n 2017, the construction industry of the region and the municipal authorities ensured housing construction at the level of 2016 - 886.9 thousand square meters. meters, while in general in Russia and in Volga Federal District the there was a decrease in housing construction volumes: in Russia - 97.9\%, in the Volga Federal District - 96.4\% of the 2016 level. The base of work of the building complex of the Penza region are the enterprises of the building industry and the building materials industry, which number more than thirty.

In recent years, there has been an increase in the value of the volume of scientific work performed. In 2016, the volume of scientific work performed amounted to 12,390.9 million rubles, which is 1.8 times more than in 2011 [4-6]. The growth rate of domestic 
expenditures on research and development in the region as a whole is not lower than the average Russian indicators (with the exception of 2014).

The main innovation activity was shown by large enterprises with more than 200 people. The share of innovation-active organizations increased from $11.0 \%$ (2011) to $20.1 \%$ (2016), and organizations implementing technological innovations increased from 9.8 to $17.5 \%$. Volume of innovative products shipped by industry organizations for 20112016 increased 2.6 times (from 3857.5 to 9972.4 million rubles). In the structure of innovative products, positive changes were observed in the direction of fundamentally new products or undergone significant technological changes (in 2016, the figure was $61.3 \%$ ). The cost structure for technological innovations in 2016 is dominated by the costs of research and development of new products, services and methods for their production, new production processes $(49.5 \%)$; on the acquisition of new technologies $(5.5 \%)$, engineering services $(7.8 \%)$, and design $(5.1 \%)$.

At the first stage, on the basis of the objectives of the expert survey, questions are resolved regarding the structure of the expert group, the number of experts and their individual qualities, in other words, the directions in which it is necessary or desirable to involve experts are determined (specialization of experts is established). Further, for each area, subgroups of experts are allocated, and the number of experts in each subgroup is established, which depends on the specific formulation of the task and should ensure the necessary coverage and completeness of aspects on each specific issue. Then, the requirements for the qualifications of experts, the length of their work in a given survey area and the overall experience are determined.

The minimum number of experts, based on the specified reliability of the result $(\mathrm{A}=$ $0.98)$, is determined as 25 .

At the second stage of the study, representatives of the construction complex of the Penza region in the amount of 25 organizations were selected, and interviewing and questioning of their management personnel were conducted in order to evaluate information on two main blocks:

-factors influencing the development of the building complex of the region;

-the main problems associated with the introduction of innovations.

The following were selected as the main respondents:

-educational institutions - 4 units,

- objects of innovation infrastructure - 4 units,

- enterprises of construction industry - 9 units,

- project organizations - 4 units,

construction enterprises - 4 units.

The survey was conducted among representatives of top management organizations respondents.

On the basis of the survey, 3 groups of factors were identified that most strongly influence the development of a construction enterprise in the current economic conditions: production, organizational, economic and managerial.

The factors selected for the expert survey:

-the presence of an innovation management system at the enterprise.

- production potential,

- readiness of the enterprise of the building complex to introduce innovations,

- the level of development of the system of training in the field of construction and the degree of its interaction with university science,

-existing building technologies,

- the level of demand for products manufactured by enterprises and potential demand for objects of innovation, 
-the presence of conditions for the development of science in the field of construction (universities, design institutes, research institutes).

-the presence of the existing mechanism of investing innovation in construction

-the degree of security machines and mechanisms.

Table 2. Indicators for calculating the innovative potential of the construction company.

\begin{tabular}{|c|c|l|}
\hline Potential & Formula & \multicolumn{1}{c|}{ Performance } \\
\hline Labor & $\mathrm{P} t r=\sqrt{\mathrm{K} r v \times \mathrm{Knt}}$ & $\begin{array}{l}\text { Krv - coefficient of use of working time of production } \\
\text { worker; } \\
\text { Kht - coefficient of labor intensity of industrial workers. }\end{array}$ \\
\hline Industrial & $\mathrm{P} p=\sqrt[3]{\mathrm{Kt} r \times \mathrm{K} m a t \times \mathrm{K} t e c h}$ & $\begin{array}{l}\text { Ktr - the utilization of labor resources; } \\
\text { Kmat - the ratio of material resources; } \\
\text { Ktech - the ratio of the availability of technical resources. }\end{array}$ \\
\hline Managerial & $\mathrm{P} u p r=\mathrm{K} s t \times \mathrm{K} t u$ & $\begin{array}{l}\text { Kst }- \text { frame stability factor; } \\
\text { Ktu - the coefficient of labor management. }\end{array}$ \\
\hline Investment & $\mathrm{P} i=R / P$ & $\begin{array}{l}\mathrm{R}-\text { the volume of attracted resources from the enterprise; } \\
\mathrm{P}-\text { the economic income of the enterprise. }\end{array}$ \\
\hline
\end{tabular}

You are free to use colour illustrations for the online version of the proceedings but any print version will be printed in black and white unless special arrangements have been made with the conference organiser. Please check whether or not this is the case. If the print version will be black and white only, you should check your figure captions carefully and remove any reference to colour in the illustration and text. In addition, some colour figures will degrade or suffer loss of information when converted to black and white, and this should be taken into account when preparing them.

\section{Conclusion}

According to the developed methodology for calculating the innovation potential, all enterprises, based on the value of the resulting indicator, can be attributed to one of three groups:

- the first group - companies with low potential (less than 0.4),

- the second group - with an average potential (from 0.41 to 0.66 ),

-Third group - with innovative potential (more than 0.67 ).

The methodology for assessing the innovative potential of an enterprise may become the basis for its further improvement.

The use of the technique is possible in the analysis of its financial and economic condition in order to increase the efficiency of its activities.

\section{References}

1. D.I. Streltsov, I.S. Artamonova, Fund.Res. 10-3, 625-629 (2015)

2. I.S. Artamonova., P.V Kolesnikov, Mod. Scient. Res. And innov. 4, 91-94 (2015)

3. I. Potekhin, V. Mischenko, A. Mottaeva, A. Zheltenkov, E3S Web of Conferences 33, 03020 (2018) doi: 10.1051/e3sconf/20183303020

4. B.B. Khustalev, A.A. Moiseeva, Competitiveness in the Global World: Economy, Science, Technology 7(2), 177-182 (2016)

5. B.B. Khustalev, Z.B. Pakhalina, M.E. Spirin, Competitiveness in the Global World: Economy, Science, Technology 8(3), 195-198 (2016)

6. I. Artamonova, A. Chernitsov, D. Osipov, et.al. J. Ponte 73-2, 1-17 (2017) 